OPEN ACCESS

Edited by: Tony Peter Craig,

The James Hutton Institute, United Kingdom

Reviewed by:

Jed J. Cohen,

Energy Institute at Johannes Kepler

University, Austria

Mehmet Efe Biresselioglu,

Ýzmir University of Economics, Turkey

${ }^{*}$ Correspondence:

Eunil Park

eunilpark@skku.edu:

pa1324@gmail.com

Specialty section:

This article was submitted to

Environmental Psychology, a section of the journal

Frontiers in Psychology

Received: 30 September 2020

Accepted: 18 December 2020

Published: 15 January 2021

Citation:

Park E (2021) Social Acceptance of Renewable Energy Technologies

in the Post-fukushima Era.

Front. Psychol. 11:612090.

doi: 10.3389/fpsyg.2020.612090

\section{Social Acceptance of Renewable Energy Technologies in the Post-fukushima Era}

\author{
Eunil Park* \\ Sungkyunkwan University, Seoul, South Korea
}

In 2011, the Fukushima nuclear accident occurred, and this had a strong effect on public perceptions of energy facilities and services that relate not only to nuclear energy, but also renewable energy resources. Moreover, the accident has also considerably affected national energy plans in both developing and developed countries. In South Korea, several studies have been conducted since the accident to investigate public perspectives toward particular energy technologies; however, few studies have investigated public perceptions of renewable-energy technologies and tracked the transitions. Therefore, this study examines the trend of South Korean public's perceptions of renewable-energy technologies. Based on data collected in 2016, we validated the structural connections and determined that trust, benefits, risks, and attitude were key determinants of the public's desire to adopt these technologies; specifically, public attitude was found to be the greatest determinant of this desire. Based on the results, both implications and limitations are examined.

Keywords: Fukushima, renewable energy, nuclear energy, social acceptance, attitude

\section{INTRODUCTION}

In March 2011, the Fukushima nuclear power plant was struck by a huge tsunami caused by a 9.0 -magnitude earthquake approximately $180 \mathrm{~km}$ east of Japan's Tohoku region. This seriously damaged the plant, resulting in three meltdowns. The nuclear accident had serious negative effects on the regional and global environment; moreover, the accident also led to a fundamental paradigm shift in most nations in regard to their energy policies (Wittneben, 2012).

The Fukushima nuclear accident also affected public perspectives toward nuclear-energy technologies and facilities; however, several studies have shown that there are notable differences in such public perceptions across different nations (Visschers and Siegrist, 2013; Bird et al., 2014; Richter et al., 2015). Furthermore, compared to the breadth of prior research on public perceptions of nuclear-energy technologies and facilities, few studies have focused on public perceptions of technologies and facilities relating to alternative energy (Cherp and Jewell, 2016; Komiyama and Fujii, 2017).

Public perception of alternative-energy sources is considered one of the most important factors influencing the investment allocated to related energy facilities and technologies within national energy plans. Moreover, these perceptions are also affected by events and accidents in other countries (Gamson and Modigliani, 1989; Verplanken, 1989). After the Fukushima accident caused significant public resistance toward nuclear energy, the majority of both developed and developing countries that were considering using nuclear energy as their main energy and electricity supply 
resource have completely reviewed and revised their national energy plans (Dhakal, 2009; Chen et al., 2014). For instance, the German government has changed its national energy policies to exclude nuclear energy from its future energy plans and the Japanese government has revised its national energy plan to exclude nuclear energy as a primary energy resource (Betzer et al., 2013; Hong et al., 2013).

The Fukushima nuclear accident allowed the public in most countries to learn of the serious negative effects of nuclear energy technologies and facilities on global environments and citizens' health (Shimura et al., 2015). Consequently, this created a public desire for the implementation of alternative energy resources in order to reduce the usage of nuclear energy. Amongst the various energy resources that are currently under consideration to replace nuclear energy, renewable-energy resources are considered to be one of the most promising (Mbarek et al., 2015).

As renewable-energy resources may play an important role in revised future energy plans, several studies have explored public perceptions of renewable energy. For example, Bang et al. (2000) found that consumer concerns toward renewable energy were notable determinants of consumer attitude toward willingness to adopt renewable energy. Painuly (2001) also indicated that there are various barriers to employing renewable energy in developing countries. In addition, the research of Mallett (2007), and Wüstenhagen and Boehnke (2008) have shown that the public's economic, sociodemographic, and psychological factors can form significant determinants of the public's desire to adopt renewableenergy technologies. However, few studies have focused on the transitions of public attitudes toward renewable-energy technologies (Park and Ohm, 2014).

In South Korea, Park and Ohm (2014) examined public perceptions of renewable energy technologies, proposed an adoption model for renewable energy technologies, and conducted pen-and-paper surveys both before and after the Fukushima nuclear accident. Before the accident, cost was one of the main reasons behind the inhibited usage of renewable-energy technologies; however, after the accident, public attitudes toward the technologies and their perceived low-degree of risk became notable determinants toward desire to adopt the technologies (Park and Ohm, 2014).

Consequently, the current study attempts to explore the following points:

1. Has there been any change in public perceptions of renewable-energy technologies since the Fukushima nuclear accident?

2. What has motivated the public to adopt renewable-energy technologies in South Korea?

In order to address the first research question, the current study reviews the findings and results of Park and Ohm (2014), conducts a pen-and-paper survey in South Korea, and tracks the notable changes in public perspectives toward renewable-energy technologies. As mentioned by Park and Ohm (2014), because there is a substitutional relationship between renewable and nuclear energy it would be worthwhile to present the effects the Fukushima nuclear accident had on public perceptions toward renewable-energy technologies and examine significant changes in the public perceptions in South Korea in this regard.

Considering the second point, the current study uses the acceptance model for renewable-energy technologies tested by Park and Ohm (2014). Based on the results of the structuralequation modeling method, we can determine the motivations behind the public adoption of the technologies, and then compare the results of the current study with those of prior studies.

The remainder of this study is organized as follows: after presenting the findings of prior studies that have focused on the adoption of renewable energy, the study methodology is examined. The results and key findings are then presented. Finally, the limitations and future studies are examined.

\section{LITERATURE REVIEW AND HYPOTHESES}

\section{Social Acceptance of Renewable Energy}

In order to respond both global warming and environmental pollutions, several nations significantly focus on both facilities and policies of alternative energy resources (Gielen et al., 2019). It means that utilizing alternative energy resources and employing a mixed energy plans are one of the important tasks in establishing the national energy policies (Dagoumas and Koltsaklis, 2019). Moreover, there have been notable efforts in using renewable energy resources for both national and local energy plans (Young and Brans, 2020).

However, there are significant economic, social, and industrial encumbrances related to utilizing renewable energy resources in the plans (Cajot et al., 2017). Among them, social perceptions of specific energy resources and technologies are considered as one of the principal issues in the regional and national levels (Paravantis et al., 2018). With no careful comprehensive procedures on specific energy-related facilities, a number of local or national conflicts can be presented (Kwon, 2018). Because of this reason, a number of researchers and public officials have investigated how to explore social perceptions of specific energy resources, including renewable energy resources (Kim et al., 2020).

Ribeiro et al. (2014) conducted a survey of public opinions on four renewable energy technologies, solar, hydro, biomass, and wind power. Considering 3,646 respondents, they found that there are a positive public perspective toward renewable energy resources, whereas NIMBY syndrome is significantly presented in the areas with biomass facilities. Moreover, they indicated that utilizing solar energy resources and employing hydropower are the appropriate desirable solutions for the economic and environmental contributions, and welfare aspects, respectively.

Liu et al. (2013) attempted to address social diffusion of renewable energy technologies in one of the rural areas in China through a field survey. Based on an analytical framework 
developed by the theory of planned behavior, they found that rural residents tend to have supportive perspectives toward renewable energy deployment with consideration of its positive relationships with environment. The results of 212 validated responses also reported that there are notable social and economic factors in determining rural residents' willing to pay for green electricity.

Bertsch et al. (2016) addressed public acceptance of renewable energy and its-related policy. Conducting a survey in Germany, both the national and local levels' determinants of adopting renewable energy sources were examined. The results of a multivariate analysis of covariance showed that there were significant differences between local and national acceptance levels, while socio-demographic information (e.g., age and education) was crucially related to the acceptance levels.

Although there are a number of prior studies on social acceptance of renewable energy resources (Kim et al., 2020), there are certain obstacles to track constant changes of social perceptions and acceptance of the resources. Because timesuitable grasping social opinions is one of the important issues (Kardooni et al., 2018), presenting both potentiality and significance of consistent tracking social opinions should be presented for governmental officers and stakeholders.

\section{Reviews on the Acceptance of Renewable Energy Facilities in Korea}

Notable quantitative studies have explored public perceptions of specific energy technologies and facilities from socialscience perspectives. For instance, McGowan and Sauter (2005) showed that, in regard to national energy plans, UK citizens preferred investment in renewable-energy facilities over nuclearenergy facilities.

Moreover, although several significant studies have investigated public attitudes and the adoption of renewableenergy technologies in regional and national perspectives, a limited number of studies have explored public attitudes and energy preferences before and after nuclear accidents, which may have notable effects on the attitudes toward and adoption of particular energy technologies as well as alternative technologies (Eiser et al., 1989). One of the most notable transitions in public attitudes and adoption occurred in the 1970s when the global oil crisis caused citizens to become concerned about their national energy plans, policies, and economy. Returning to the present, in South Korea, Park and Ohm (2014) proposed an integrated research model for adopting renewable-energy technologies, and captured the significant transitions in public attitudes between the periods before and after the Fukushima accident. Considering seven factors, the main determinants of public desire to adopt renewable-energy technologies changed from cost to attitude.

For investigating the transitions, surveying citizens' opinions is considered one of the most accurate and successful research approaches. Consequently, the current study employs the conceptual research model previously validated by Park and Ohm (2014), and captures the notable changes in public perceptions of renewable-energy technologies over time. In the research model of Park and Ohm (2014), the following hypotheses are considered (Figure 1):

H1. A higher degree of attitude leads to a higher degree of desire to adopt.

H2. A higher degree of perceived trust leads to a higher degree of perceived benefits.

H3. A higher degree of perceived trust leads to a lower degree of perceived risks.

H4. A higher degree of knowledge leads to a higher degree of perceived benefits.

H5. A higher degree of knowledge leads to a lower degree of perceived risks.

H6. A higher degree of perceived benefits leads to a higher degree of public attitude.

H7. A higher degree of perceived risks leads to a lower degree of public attitude.

H8. A higher degree of perceived cost leads to a lower degree of desire to adopt.

\section{STUDY METHOD}

\section{Survey Design and Procedure}

Following the procedures of the survey-design methodology used by Park and Ohm (2014), the current study employed identical questionnaire items to those used in the main survey of Park and Ohm (2014).

We followed all procedures presented by Park and Ohm (2014): (1) exploring unique characteristics, (2) presenting selected constructs, (3) examining the potentiality and validity of the constructs, (4) conducting a pilot test with validity tests, and (5) presenting the survey.

In addition to two-time survey sessions in 2010 and 2012, which were conducted in prior studies (Park and Ohm, 2014), we conducted additional survey in 2016. All questionnaire items, sampling procedures and outliner filtering methodologies (a stratified quota sampling) were identical with prior survey sessions in 2010 and 2012. The survey was distributed to 1,500 potential respondents in 6 regions and 18 cities in South Korea. In order to ensure the representativeness of the

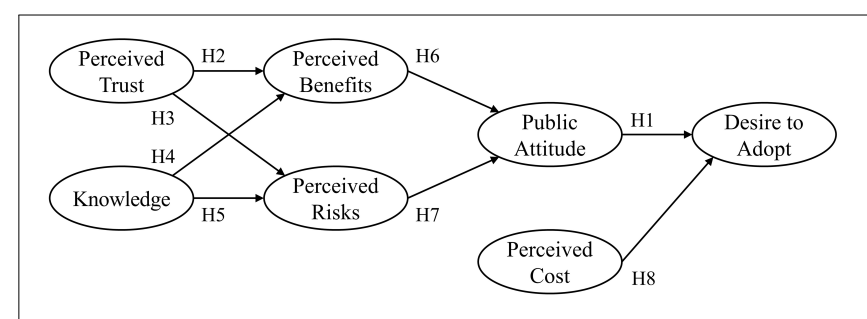

FIGURE 1 | The proposed research model used in this study. 
sample in the survey, the current study applied a stratified quotasampling method. After excluding incomplete and invalidated responses, 991 (66.1\% of response rate) samples were used in the statistical analysis.

\section{Measurements}

All measurements in this study were validated by prior studies (Park and Ohm, 2014). All participants were instructed to mark each item with a 7-point Likert scale (7: strongly agree/1: strongly disagree). The perceived trust was examined by three items (Cronbach's alpha: 0.890; e.g., "I believe that renewable energy technologies can improve our energy generation industry successfully."). Three items contributed to the perceived benefits (Cronbach's alpha: 0.912; e.g., "Renewable energy technologies may help us develop increased industrial competitive advantages."). Moreover, the perceived cost was presented by three items (Cronbach's alpha: 0.888; e.g., "I think the maintenance cost of using renewable energy technologies and generators is expensive"), while three items composed the perceived risks (Cronbach's alpha: 0.921; e.g., "Renewable energy technologies and plants can harm our society including animals and plants."). Three items were employed to examine the desire to adopt (Cronbach's alpha: 0.909; e.g., "If I could, I would prefer to use renewable energy technologies and generators."). The public attitude was presented by three items (Cronbach's alpha: 0.879; e.g., "Applying renewable energy technologies is extremely good for us"). Lastly, the public knowledge was organized by three items (Cronbach's alpha: 0.904; e.g., "how familiar are you with renewable energy sources and technologies?").

\section{DATA ANALYSIS}

A structural-equation modeling (SEM) method was used to capture the structural changes in the research model. In addition, by computing the total effects of the factors relating to approval and comparing the results of the computations and SEM (2010, 2012, and 2016), the current study aims to track significant changes in the structural relationships within the research model.

\section{RESULTS}

\section{Analysis Methods}

The connections in the research model were examined and analyzed using SEM. In order to test the reliability of the employed constructs, we employed confirmatory-factor analysis. The current study meets the recommendations of previous SEM studies in regard to internal (all Cronbach's alphas were higher than 0.7), convergent (all factor loadings, composite reliability, and average variance extracted values were higher than $0.7,0.7$, and 0.5 , respectively), and discriminant reliability tests (The correlation values between two specific

TABLE 1 | The fit indices of the measurement and research models (M: The measurement model, R: The research model; Anderson and Gerbing, 1988; Bagozzi and Yi, 1988; Jöreskog and Sörbom, 1996; Kenny and McCoach, 2003; Hoe, 2008).

\begin{tabular}{|c|c|c|c|c|}
\hline \multirow[t]{2}{*}{ Fit indices } & \multirow{2}{*}{$\begin{array}{c}\text { Before the Fukushima accident } \\
2010\end{array}$} & \multicolumn{2}{|c|}{ Post-Fukushima } & \multirow[t]{2}{*}{ Satisfaction levels } \\
\hline & & 2012 & 2016 & \\
\hline$x^{2} /$ d.f. & $4.08^{M}, 4.07^{R}$ & $4.44^{M}, 4.01^{R}$ & $4.32^{M}, 4.32^{R}$ & $<5.00$ \\
\hline Normed fit index & $0.94^{M}, 0.95^{R}$ & $0.91^{M}, 0.93^{R}$ & $0.90^{M}, 0.90^{R}$ & $>0.80$ \\
\hline Incremental fit index & $0.97^{M}, 0.96^{R}$ & $0.94^{M}, 0.91^{R}$ & $0.92^{M}, 0.92^{R}$ & $>0.90$ \\
\hline Comparative fit index & $0.94^{M}, 0.94^{R}$ & $0.92^{M}, 0.90^{R}$ & $0.92^{M}, 0.91^{R}$ & $>0.80$ \\
\hline Goodness-of-fit index & $0.95^{M}, 0.94^{R}$ & $0.96^{M}, 0.92^{R}$ & $0.93^{M}, 0.90^{R}$ & $>0.80$ \\
\hline Adjusted goodness-of-fit index & $0.95^{M}, 0.95^{R}$ & $0.95^{M}, 0.94^{R}$ & $0.93^{M}, 0.92^{R}$ & $>0.80$ \\
\hline Standardized root mean square residual & $0.05^{M}, 0.06^{R}$ & $0.05^{M}, 0.05^{R}$ & $0.07^{M}, 0.07^{R}$ & $<0.08$ \\
\hline Root mean square error of approximation & $0.04^{M}, 0.05^{R}$ & $0.05^{M}, 0.05^{R}$ & $0.06^{M}, 0.07^{R}$ & $<0.08$ \\
\hline
\end{tabular}

TABLE 2 | Summary of the structural results from $2016\left({ }^{*} p<0.001\right)$.

\begin{tabular}{|c|c|c|c|c|}
\hline Hypothesis & Standardized path coefficient & SE & CR & Results \\
\hline H1. Attitude $\rightarrow$ Adoption & $0.821^{\star}$ & 0.038 & 81.712 & Supported \\
\hline H2. Trust $\rightarrow$ Benefits & $0.517^{\star}$ & 0.041 & 68.105 & Supported \\
\hline H3. Trust $\rightarrow$ Risks & $-0.135^{\star}$ & 0.029 & -5.877 & Supported \\
\hline H4. Knowledge $\rightarrow$ Benefits & -0.103 & 0.037 & -4.789 & Not supported \\
\hline H5. Knowledge $\rightarrow$ Risks & -0.078 & 0.045 & -2.822 & Not supported \\
\hline H6. Benefits $\rightarrow$ Attitude & $0.518^{\star}$ & 0.044 & 72.988 & Supported \\
\hline H7. Risks $\rightarrow$ Attitude & $-0.694^{*}$ & 0.025 & -79.218 & Supported \\
\hline H8. Cost $\rightarrow$ Adoption & $-0.409^{*}$ & 0.031 & -45.766 & Supported \\
\hline
\end{tabular}

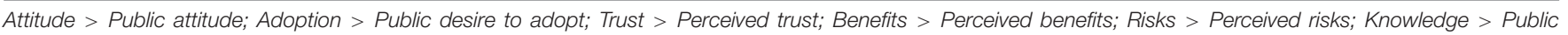
knowledge; Cost $>$ Perceived cost. 
constructs were lower than the square rots of the average variance extracted).

\section{Fit Indices}

The current study computed the fit indices of the measurement and research models by considering if the collected data were well-represented by the measurement and research models. The fit indices of the measurement and research models were found to be acceptable (Table 1).

\section{Hypothesis Testing}

\section{Structural Results of the Research Model}

The structural results of the research model are summarized in Table 2, and a comparison is presented in Figure 2. The results of the data that was collected in 2016 supported six hypotheses, while two hypotheses concerning knowledge-benefits and knowledge-risks were not significant $(\mathrm{H} 4, \beta=-0.103$, $C R=-4.789, p>0.05 ; \mathrm{H} 5, \beta=-0.078, C R=-2.822$, $p>0.5)$. Public desire to adopt renewable technologies was significantly determined by two factors, public attitude and perceived cost, while the effects of public attitude on the desire to adopt ( $\mathrm{H} 1, \beta=0.821, C R=81.712, p<0.001)$ were greater than those of perceived cost $(\mathrm{H} 8, \beta=-0.409, \mathrm{CR}=-45.766$, $p<0.001)$. Perceived benefits had positive effects on the attitude (H6, $\beta=0.518, C R=72.988, p<0.001$ ), while the attitude was negatively affected by perceived risks (H7, $\beta=-0.694$, $C R=-79.218, p<0.001)$.

\section{Sum of Total Absolute Effects on the Intention}

In order to present the key motivations behind users' attitudes toward renewable-energy technologies, the total standardized effects of motivations and barriers in regard to this attitude were computed. Table 3 and Figure 3 present a summary of the total effects on desire to adopt. Although the effect perceived cost had

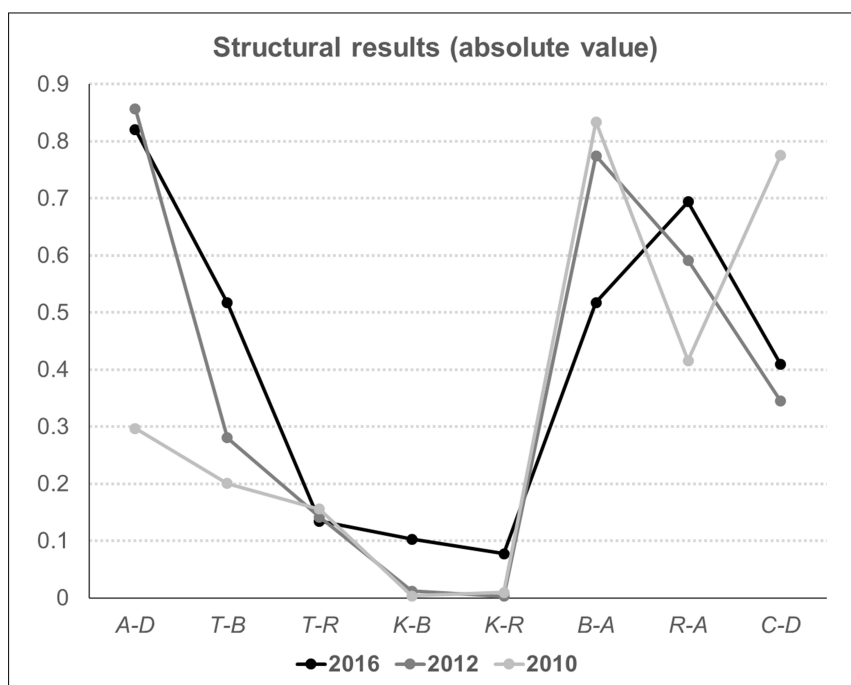

FIGURE 2 | Summary of the results from 2010, 2012, and 2016 (A > Attitude; $\mathrm{D}>$ Public desire to adopt; $T$ > Perceived trust; $\mathrm{B}>$ Perceived benefits; $\mathrm{R}>$ Perceived risks; $\mathrm{K}>$ Public knowledge; $\mathrm{C}>$ Perceived cost).
TABLE 3 | Total standardized effects on the desire to adopt.

\begin{tabular}{ccccccc}
\hline Year & Trust & Knowledge & Benefits & Risks & Attitude & Cost \\
\hline 2016 & 0.297 & 0.088 & 0.425 & 0.570 & 0.821 & 0.409 \\
2012 & 0.259 & 0.009 & 0.664 & 0.507 & 0.857 & 0.345 \\
2010 & 0.069 & 0.002 & 0.248 & 0.124 & 0.297 & 0.776
\end{tabular}

Trust > Perceived trust; Knowledge > Public knowledge; Benefits > Perceived benefits; Risks > Perceived risks; Attitude > Public attitude; Cost > Perceived cost.

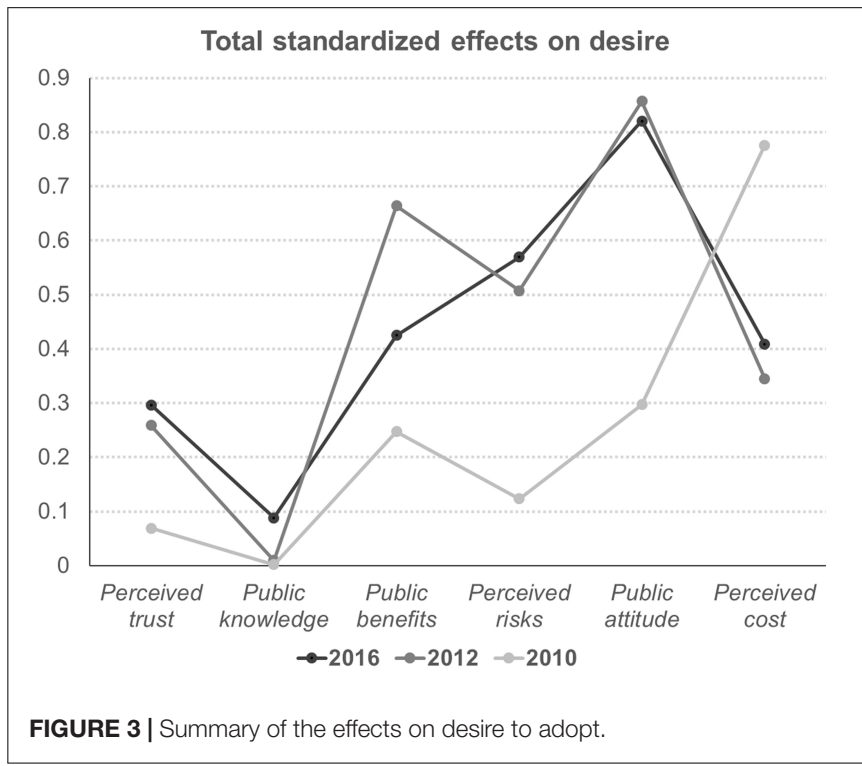

TABLE 4 | Total standardized effects on attitude.

\begin{tabular}{ccccc}
\hline Year & Trust & Knowledge & Benefits & Risks \\
\hline 2016 & 0.362 & 0.107 & 0.518 & 0.694 \\
2012 & 0.302 & 0.011 & 0.775 & 0.592 \\
2010 & 0.233 & 0.007 & 0.834 & 0.416 \\
\hline
\end{tabular}

Trust > Perceived trust; Knowledge > Public knowledge; Benefits > Perceived benefits; Risks > Perceived risks.

on desire to adopt significantly diminished between 2010 and $2012(0.776 \rightarrow 0.345)$, it became moderately influential in 2016 (0.409). Compared to the role of cost, public attitude consistently remained a main determinant of desire to adopt $(0.821$ in 2016). The effects of perceived risks of adoption are becoming more important $(0.124$ in $2010 \rightarrow 0.507$ in $2012 \rightarrow 0.570$ in 2016), while the effects of perceived benefits of adoption are abating $(0.248 \rightarrow 0.664 \rightarrow 0.425)$. Although public knowledge of renewable-energy technologies has been increasing, the effects of public knowledge are still lower than those of perceived trust (0.088 and 0.297).

\section{Sum of Total Absolute Effects on the Attitude}

The transitions of the effects of perceived trust, public knowledge, public benefits, and perceived risks on public desire to adopt renewable-energy technologies were quite similar to those concerning attitude. In addition, public attitude played a notable role in affecting desire to adopt, while the effects of perceived 


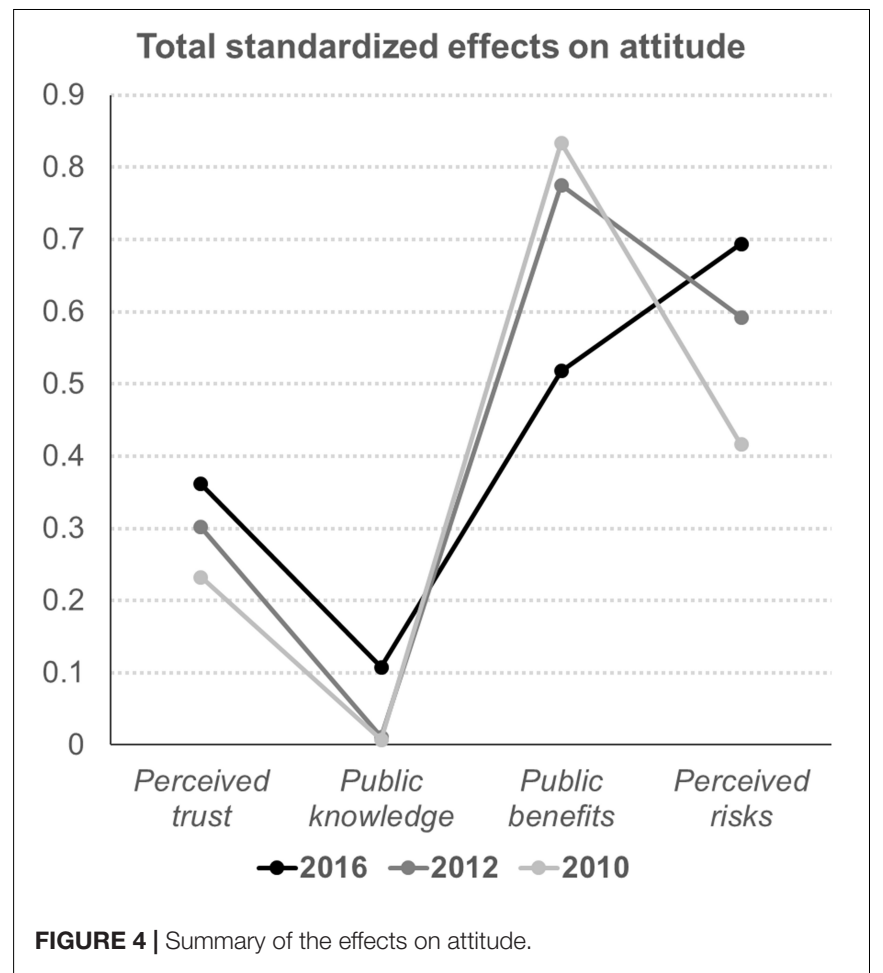

cost on desire to adopt have increased. Similar to the effects of the constructs on adoption, the roles of public knowledge, perceived trust, and risks in regard to determining public attitude have also been growing in importance (Table $\mathbf{4}$ and Figure 4 ). However, the effects of perceived benefits on attitude have reduced $(0.775 \rightarrow 0.518)$.

\section{CONCLUSION}

This study aims to track users' perceptions of renewable-energy technologies in the "post-Fukushima era." Based on the findings of a previously conducted study on the South Korean public's perception of such technologies, this study re-examines the research model used in this previous study and investigates the effects of the employed antecedents on public attitude toward and desire to adopt renewable-energy technologies. This study aimed to track the effects the Fukushima nuclear accident had on public perspectives toward renewable-energy technologies in South Korea. As previous studies, both before and after the incident, have fragmentarily observed public perceptions on such technologies, this study conducted a survey in 2016, 5 years after the accident. Then, we compared the results of the data collected by the survey and the results of previous studies. Two factors, the perceived risks and benefits, significantly affected the attitude, while the risks and benefits were mainly determined by perceived trust in the technologies. Although two factors, the risks and benefits, which were confirmed in prior research as determinants of public desire to adopt such technologies, are also presented in this study as the antecedents of the desire to adopt, there are notable transitions in the post-Fukushima era (Park and Ohm, 2014).

Since the Fukushima nuclear accident, the South Korea public has tended to adopt more risk-oriented perspectives toward particular energy technologies. It means that H7 was magnified after the Fukushima accident in South Korea [Total standardized effects (TSE): $0.416(2010) \rightarrow 0.592(2012) \rightarrow 0.694$ (2016)]. In regard to motivations, a more comprehensive understanding of perceived trust is developing ( $\mathrm{H} 2$ and $\mathrm{H} 3$ ); moreover, public knowledge of renewable-energy technologies is becoming important in forming public attitude toward and desire to adopt the technologies [H4 and H5; TSE: 0.007 (2010) $\rightarrow 0.011$ (2012) $\rightarrow 0.107$ (2016)].

This means that citizens are becoming familiar with renewable-energy technologies, and are beginning to understand the potential risks and benefits of such technologies (H7). Although the Fukushima nuclear accident, which occurred in a country close to South Korea, was not directly associated with renewable-energy technologies, the results of the current study provide notable evidence that the incident has continually and consistently influenced the public's perceptions of particular energy technologies.

Moreover, the results from 2016 also contribute to providing a better understanding of the sequential relationships of users' perceived trust-benefits and risks, attitude, and desire to adopt, and also show the significant roles perceived risk and trust in renewable-energy technologies play in regard to the diffusion, distribution, and success of the technologies in South Korea.

\section{IMPLICATIONS, LIMITATIONS, AND FUTURE STUDIES}

Consistent with the findings of prior studies, the current study validates the structural connections between desire to adopt, attitude, benefits (and risks), and trust in renewable-energy technologies in South Korea. However, some transitions were observed in 2016 that conflicted with the results from 2010 and 2012. Two variables, public attitude and perceived cost, still affect public desire to adopt renewable-energy technologies; however, perceived risk is becoming more important. Although public benefits is still significant, its significance in determining public attitude has become more moderate compared to its status in 2010 and 2012.

Although the Fukushima accident does not have direct connections with renewable-energy technologies, it has led to notable lessons for the public. After the accident, the potential risks of energy technologies, which are mainly dependent on perceived trust, are beginning to become one of the most significant determinants of public attitude. Moreover, the key determinant of public attitude has changed from perceived benefits to risks. This means that citizens are more concerned about the potential harmfulness of energy technologies than their advantages. Although the effects of public knowledge are slight, the importance and significance of this knowledge are increasing.

As presented in the results, trust is still the key determinant of benefits and risks. This means that the South Korean government 
and its industry should be more responsible and make its national energy plans sustainable and eco-friendly, focusing on the distribution of renewable-energy technologies and aiding public usage and consumption of the technologies.

In effect, the government and industry should focus on the revision of legislation, the enforcement of ordinances and regulations, the provision of subsidies and benefits, and the incubation of social trust in renewable-energy technologies. Moreover, the government should include the public as one of the key participants in the decision-making process concerning the revision, provision, and incubation of energy policies.

Although the current study presents some findings, there are several limitations. First, for several reasons, it is not easy to generalize the results of the current study. For example, because the survey described in this study was conducted in South Korea, regional and cultural characteristics may have had an effect on the public's perceptions. Second, the current study applies a research model for public perceptions that was validated in prior research along with the motivations tested therein (Park and Ohm, 2014). Several studies have indicated that other motivations can be significantly related to the adoption of energy technologies (Assefa and Frostell, 2007; Huijts et al., 2012). Consequently, future research should address these limitations and extend the findings of the current study.

\section{REFERENCES}

Anderson, J. C., and Gerbing, D. W. (1988). Structural equation modeling in practice: a review and recommended two-step approach. Psychol. Bull. 103, 411-423. doi: 10.1037/0033-2909.103.3.411

Assefa, G., and Frostell, B. (2007). Social sustainability and social acceptance in technology assessment: a case study of energy technologies. Technol. Soc. 29, 63-78. doi: 10.1016/j.techsoc.2006.10.007

Bagozzi, R. P., and Yi, Y. (1988). On the evaluation of structural equation models. J. Acad. Mark. Sci. 16, 74-94.

Bang, H. K., Ellinger, A. E., Hadjimarcou, J., and Traichal, P. A. (2000). Consumer concern, knowledge, belief, and attitude toward renewable energy: an application of the reasoned action theory. Psychol. Mark. 17, 449-468. doi: 10.1002/(sici)1520-6793(200006)17:6<449::aid-mar2>3.0.co;2-8

Bertsch, V., Hall, M., Weinhardt, C., and Fichtner, W. (2016). Public acceptance and preferences related to renewable energy and grid expansion policy: empirical insights for Germany. Energy 114, 465-477. doi: 10.1016/j.energy. 2016.08.022

Betzer, A., Doumet, M., and Rinne, U. (2013). How policy changes affect shareholder wealth: the case of the Fukushima Dai-ichi nuclear disaster. Appl. Econ. Lett. 20, 799-803. doi: 10.1080/13504851.2012.74 8172

Bird, D. K., Haynes, K., van den Honert, R., McAneney, J., and Poortinga, W. (2014). Nuclear power in Australia: a comparative analysis of public opinion regarding climate change and the Fukushima disaster. Energy Policy 65, 644653. doi: 10.1016/j.enpol.2013.09.047

Cajot, S., Peter, M., Bahu, J. M., Guignet, F., Koch, A., and Maréchal, F. (2017). Obstacles in energy planning at the urban scale. Sustain. Cities Soc. 30, 223-236. doi: $10.1016 /$ j.scs.2017.02.003

Chen, W. M., Kim, H., and Yamaguchi, H. (2014). Renewable energy in eastern Asia: renewable energy policy review and comparative SWOT analysis for promoting renewable energy in Japan, South Korea, and Taiwan. Energy Policy 74, 319-329. doi: 10.1016/j.enpol.2014.08.019

Cherp, A., and Jewell, J. (2016). Energy policy: renewables targeted before Fukushima. Nature 533:36. doi: 10.1038/533036b

\section{DATA AVAILABILITY STATEMENT}

All datasets generated for this study are included in the article/supplementary material, further inquiries can be directed to the corresponding author/s.

\section{ETHICS STATEMENT}

The studies involving human participants were reviewed and approved by the Department of Interaction Science, Sungkyunkwan University. The patients/participants provided their written informed consent to participate in this study.

\section{AUTHOR CONTRIBUTIONS}

EP fully conducted and wrote the manuscript.

\section{FUNDING}

This research was also supported by the National Research Foundation of Korea (NRF) funded by the Korea Government (NRF-2018S1A5A8027730 and NRF-2020R1C1C1004324).

Dagoumas, A. S., and Koltsaklis, N. E. (2019). Review of models for integrating renewable energy in the generation expansion planning. Appl. Energy 242, 1573-1587. doi: 10.1016/j.apenergy.2019.03.194

Dhakal, S. (2009). Urban energy use and carbon emissions from cities in China and policy implications. Energy policy 37, 4208-4219. doi: 10.1016/j.enpol.2009.05. 020

Eiser, J. R., Spears, R., and Webley, P. (1989). Nuclear attitudes before and after chernobyl: change and judgment. J. Appl. Soc. Psychol. 19, 689-700. doi: 10. 1111/j.1559-1816.1989.tb00348.x

Gamson, W. A., and Modigliani, A. (1989). Media discourse and public opinion on nuclear power: a constructionist approach. Am. J. Sociol. 95, 1-37. doi: $10.1086 / 229213$

Gielen, D., Boshell, F., Saygin, D., Bazilian, M. D., Wagner, N., and Gorini, R. (2019). The role of renewable energy in the global energy transformation. Energy Strategy Rev. 24, 38-50. doi: 10.1016/j.esr.2019.01.006

Hoe, S. L. (2008). Issues and procedures in adopting structural equation modeling technique. J. Appl. Quant. Methods 3, 76-83.

Hong, S., Bradshaw, C. J., and Brook, B. W. (2013). Evaluating options for the future energy mix of Japan after the Fukushima nuclear crisis. Energy Policy 56, 418-424. doi: 10.1016/j.enpol.2013.01.002

Huijts, N. M., Molin, E. J., and Steg, L. (2012). Psychological factors influencing sustainable energy technology acceptance: a review-based comprehensive framework. Renew. Sustain. Energy Rev. 16, 525-531. doi: 10.1016/j.rser.2011. 08.018

Jöreskog, K. G., and Sörbom, D. (1996). LISREL 8: User's Reference Guide. Skokie, IL: Scientific Software International.

Kardooni, R., Yusoff, S. B., Kari, F. B., and Moeenizadeh, L. (2018). Public opinion on renewable energy technologies and climate change in Peninsular Malaysia. Renew. Energy 116, 659-668. doi: 10.1016/j.renene.2017.09.073

Kenny, D. A., and McCoach, D. B. (2003). Effect of the number of variables on measures of fit in structural equation modeling. Struct. Equ. Modeling 10, 333-351. doi: 10.1207/s15328007sem1003_1

Kim, J., Jeong, D., Choi, D., and Park, E. (2020). Exploring public perceptions of renewable energy: evidence from a word network model in social network services. Energy Strategy Rev. 32:100552. doi: 10.1016/j.esr.2020.100552 
Komiyama, R., and Fujii, Y. (2017). Assessment of post-Fukushima renewable energy policy in Japan's nation-wide power grid. Energy Policy 101, 594-611. doi: 10.1016/j.enpol.2016.11.006

Kwon, T. H. (2018). Policy synergy or conflict for renewable energy support: case of RPS and auction in South Korea. Energy Policy 123, 443-449. doi: 10.1016/j.enpol.2018.09.016

Liu, W., Wang, C., and Mol, A. P. (2013). Rural public acceptance of renewable energy deployment: the case of Shandong in China. Appl. Energy 102, 11871196. doi: 10.1016/j.apenergy.2012.06.057

Mallett, A. (2007). Social acceptance of renewable energy innovations: the role of technology cooperation in urban Mexico. Energy Policy 35, 2790-2798. doi: 10.1016/j.enpol.2006.12.008

Mbarek, M. B., Khairallah, R., and Feki, R. (2015). Causality relationships between renewable energy, nuclear energy and economic growth in France. Environ. Syst. Decis. 35, 133-142. doi: 10.1007/s10669-015-9537-6

McGowan, F., and Sauter, R. (2005). Public Opinion On Energy Research: A Desk Study For The Research Councils. Brighton: University of Sussex.

Painuly, J. P. (2001). Barriers to renewable energy penetration; a framework for analysis. Renew. Energy 24, 73-89. doi: 10.1016/s0960-1481(00)00186-5

Paravantis, J. A., Stigka, E., Mihalakakou, G., Michalena, E., Hills, J. M., and Dourmas, V. (2018). Social acceptance of renewable energy projects: a contingent valuation investigation in Western Greece. Renew. Energy 123, 639-651. doi: 10.1016/j.renene.2018.02.068

Park, E., and Ohm, J. Y. (2014). Factors influencing the public intention to use renewable energy technologies in South Korea: effects of the Fukushima nuclear accident. Energy Policy 65, 198-211. doi: 10.1016/j.enpol.2013.10.037

Ribeiro, F., Ferreira, P., Araújo, M., and Braga, A. C. (2014). Public opinion on renewable energy technologies in Portugal. Energy 69, 39-50. doi: 10.1016/j. energy.2013.10.074

Richter, F., Steenbeck, M., and Wilhelm, M. (2015). The Fukushima Accident and Policy Implications: Notes on Public Perception in Germany, No. 045. Available online at: http://econpapers.repec.org/paper/hcewpaper/045.htm (accessed January 19, 2015).
Shimura, T., Yamaguchi, I., Terada, H., Svendsen, E. R., and Kunugita, N. (2015). Public health activities for mitigation of radiation exposures and risk communication challenges after the Fukushima nuclear accident. J. Radiat. Res. 56, 422-429. doi: 10.1093/jrr/rrv013

Verplanken, B. (1989). Beliefs, attitudes, and intentions toward nuclear energy before and after Chernobyl in a longitudinal within-subjects design. Environ. Behav. 21, 371-392. doi: 10.1177/0013916589214001

Visschers, V. H., and Siegrist, M. (2013). How a nuclear power plant accident influences acceptance of nuclear power: results of a longitudinal study before and after the Fukushima disaster. Risk Anal. 33, 333-347. doi: 10.1111/j.15396924.2012.01861.x

Wittneben, B. B. (2012). The impact of the Fukushima nuclear accident on European energy policy. Environ. Sci. Policy 15, 1-3. doi: 10.1016/j.envsci.2011. 09.002

Wüstenhagen, R., and Boehnke, J. (2008). Business Models for Sustainable Energy. Available online at: https://www.taylorfrancis.com/chapters/business-modelssustainable-energy-rolf-w\%C3\%BCstenhagen-jasper-boehnke/e/10.4324/ 9781351280204-11 (accessed February 24, 2017).

Young, J., and Brans, M. (2020). Fostering a local energy transition in a postsocialist policy setting. Environ. Innov. Soc. Transit. 36, 221-235. doi: 10.1016/ j.eist.2020.05.003

Conflict of Interest: The author declares that the research was conducted in the absence of any commercial or financial relationships that could be construed as a potential conflict of interest.

Copyright (C) 2021 Park. This is an open-access article distributed under the terms of the Creative Commons Attribution License (CC BY). The use, distribution or reproduction in other forums is permitted, provided the original author(s) and the copyright owner(s) are credited and that the original publication in this journal is cited, in accordance with accepted academic practice. No use, distribution or reproduction is permitted which does not comply with these terms. 